\title{
Design and Testing of the Power Electronics for the Cannon Caliber Electromagnetic Gun System
}

\author{
By: \\ C.E. Penney \\ T.J. Hotz
}

Presented at the 8th Electromagnetic Launch Symposium, Baltimore, MD, April 22-24, 1996.

IEEE Transactions on Magnetics, vol 33, no 1, Jan 1997.

PR - 217

Center for Electromechanics

The University of Texas at Austin

PRC, Mail Code R7000

Austin, TX 78712

(512) 471-4496 


\title{
Design and Testing of the Power Electronics for the Cannon Caliber Electromagnetic Gun System
}

\author{
C. E. Penney, T. J. Hotz, J. R. Kitzmiller, and M. D. Werst \\ The University of Texas at Austin, Center for Electromechanics, Austin, Texas
}

\begin{abstract}
The University of Texas Center for Electromechanics (UT-CEM) is in the final fabrication and testing phase of a power electronics system required to operate a skid mounted compulsator-driven railgun. Design goals for the self-excited air core compulsator include a 95 MW rectifier/inverter bridge for field coil self-excitation. Initial field coil seed energy is supplied by a $50 \mathrm{~kJ}$ capacitive discharge from the field initiation module. The field coil is passively protected from voltage transients by an array of metal oxide varistors. Other system power modules include the gun closing switch and explosive opening switch. This paper presents a brief system overview and detailed design of the rectifier/inverter bridge module with performance data from shots up to \#6.
\end{abstract}

\section{INTRODUCTION}

UT-CEM has completed fabrication and is currently testing a lightweight air-core compulsator driving a cannon caliber electromagnetic gun (CCEMG). The final mechanical fabrication and preliminary testing results are presented in references $[1,2]$. This paper will present a brief system overview and detailed design of the rectifier/inverter bridge module with available performance data.

UT-CEM has fabricated a four-pole, air core compulsator and has tested the machine to 8,250 rpm. This power supply drives a $2.25 \mathrm{~m}$, augmented railgun capable of launching 15 , $185 \mathrm{~g}$ projectiles at a velocity of $1,850 \mathrm{~m} / \mathrm{s}$. The 15 -shot sequence will be accomplished with three, $1 \mathrm{~s}$, five-shot salvos with $2.5 \mathrm{~s}$ between salvos. At the time of writing this paper, only single-shot testing has been completed to a level of $1,900 \mathrm{~m} / \mathrm{s}$.

Manuscript received April 8, 1996.

C. E. Penney, e-mail c.penney@mail.utexas.edu, phone number (512) 471-4496, fax (512) 471-0781; T. J. Hotz, e-mail t.hotz@mail.utexas.edu., J. R. Kitzmiller e-mail kitzmiller@crovax.cem.utexas.edu, phone number (512) 471-4496, (512) 471-0781.

This effort is funded by the U.S. Army Armament Research Development and Engineering Center and the U.S. Marine Corps.
The CCEMG system uses five different but unique switching mechanisms for the distribution of current during a launch. An overall system schematic is shown in Fig. 1. The air-core compulsator is a self-excited machine and a $50 \mathrm{~kJ}$ field initiation module (FIM) produces a seed current for the field coil. The FIM consists of two 3,500 $\mu \mathrm{F}$ capacitors charged to $4 \mathrm{kV}$ and switched by dual $4.5 \mathrm{kV}$ thyristors. The FIM is passively recharged during the rectification phase using anti-parallel high voltage diodes with appropriate resistive current limiting.

Once the firing and fault control monitor (FFCM) has detected adequate FIM charging of the field coil, rectification is initiated. Rectification and inversion are achieved using a 95 MW thyristor bridge. Each leg consists of six $3.8 \mathrm{kV}$ thyristors stacked in two sets of three parallel devices with a peak forward operating current of $25 \mathrm{kA}$ at a $50 \%$ duty cycle. The bridge was designed to stand-off sinusoidal voltage of 3.8

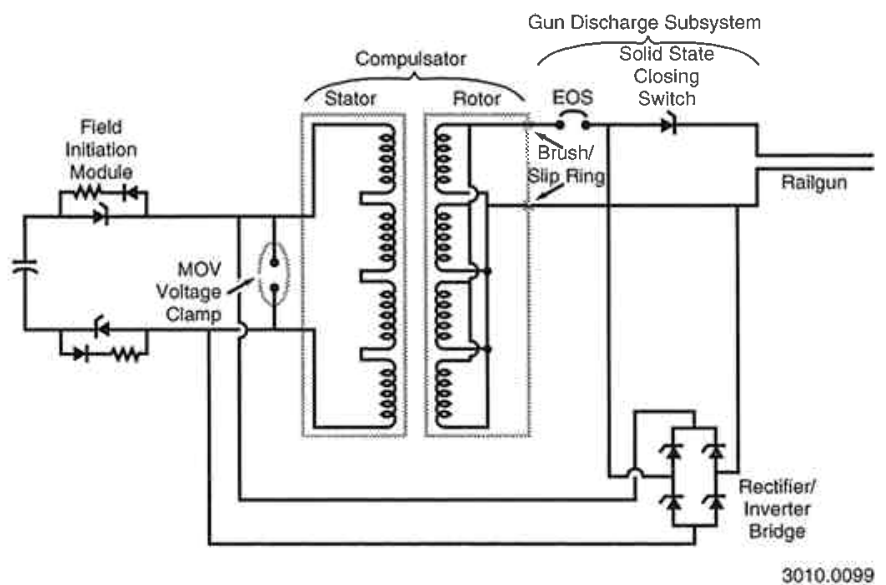

Fig. 1. Overall CCEMG system schematic 
$\mathrm{kV}$. The thyristor bridge not only serves the purpose of rectification but also freewheels during launching and is used as an inverter for field reclamation between rounds. The three tasks of the rectifier/inverter bridge are controlled by the FFCM.

Once the FFCM has detected the field coil level defined by the mission parameters, the rectifier/inverter bridge begins freewheeling and the gun pulse is produced by the gun switch module (GSM). The GSM consists of 40 parallel $4.5 \mathrm{kV}$ thyristors designed for pulse duty with a forward surge of 825 $\mathrm{kA}$ [3]. The $77 \mathrm{~mm}$ thyristors are arranged in a five layer, interleaved, cylindrical geometry. As the launch package exits the gun, a muzzle crowbar switch with a similar design will be used to snub the muzzle arc. The forward surge rating for the solid-state muzzle crowbar is only $250 \mathrm{kA}$.

An explosively operated opening switch (EOS) is used for overcurrent and thermal protection of the compulsator and all solid state switches. The EOS is designed to be able to handle the current and action demands of both the field coil and gun circuits. This switch is a semi-circle shaped piece of aluminum with multiple gaps loaded with Primacord ${ }^{\circledR}$. The switch is initiated using standard exploding bridgewire detonators. The EOS is also designed to passively open thermally upon an overcurrent condition inside the compulsator. Therefore the EOS must be able to adequately dissipate all of the inductively stored energy in the system. The physical layout of the power electronics skid can be seen in Fig. 2.

\section{RECTIFIER/INVERTER BRIDGE}

Field coil excitation and regenerative field coil dump for the compulsator is achieved using a full wave, single phase rectifier/inverter (R/I) bridge. In the CCEMG system, the initial field coil current is supplied by a capacitor discharge. As the compulsator main armature voltage increases above the threshold for self-excitation, ac current from the armature is

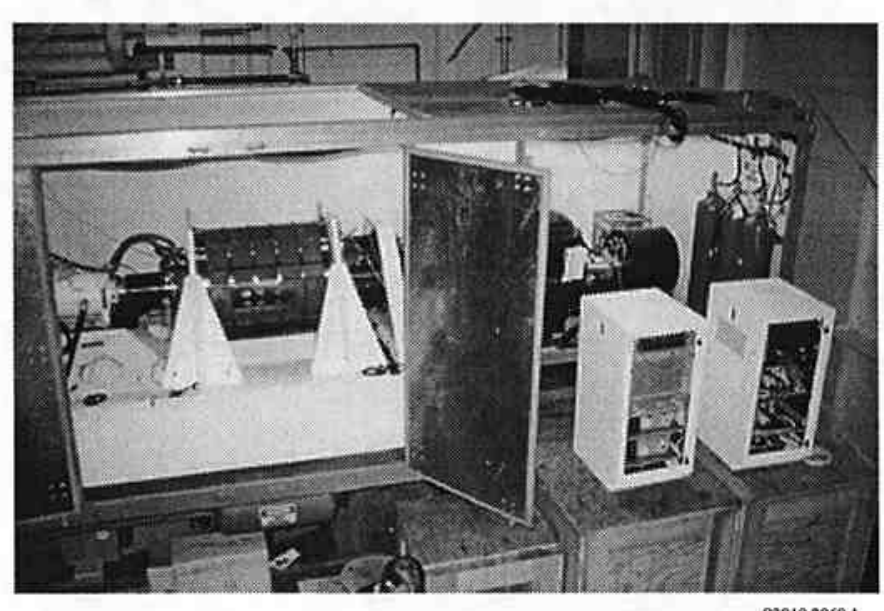

$\$ 3010.2050 .1$

Fig. 2. Layout of CCEMG power electronics skid rectified and charges the field coil. Depending on rotor speed and desired field coil current, rectification can last for 50 to $150 \mathrm{~ms}$. In addition to rectification, the bridge also performs inversion. After a discharge, the bridge switches to inverter mode thus reclaiming remaining field coil energy and returning it to the rotor where it is stored as increased kinetic energy. Again, depending on rotor speed and the level of field coil current, inversion will last for 50 to $150 \mathrm{~ms}$. The combined duties of rectification and inversion yield a requirement for a quasi-steady state bridge operation with an instantaneous peak power of $95 \mathrm{MW}$.

Overall system efficiency was an important consideration in the design of the CCEMG project. The reclamation of field coil current was important to increase efficiency as well as reduce the thermal demands on the bridge and the buswork. The efficiency of the bridge is highly dependent on the thyristor turn-off time. In selecting the bridge thyristors, fast turnoff time and high action capacity were the main criteria. Several candidate devices from different manufactures were evaluated. The selected thyristor is a Powerex TD-20. The device is a $100 \mathrm{~mm}$ unit with a $3,800 \mathrm{~V}$ rating with surge rating of $56 \mathrm{kA}$ and an action rating of $1.3 \times 10^{7} \mathrm{~A}^{2} \mathrm{~s}$. A final configuration of two sets of three in parallel for a total of six thyristors is shown in Fig. 3. The combined thyristor data sheet values yield these parameters for the bridge:

$\begin{aligned} & \text { Peak current (surge): } 138 \mathrm{kA} \\ & \text { Peak voltage: } 7.6 \mathrm{kV} \\ & \text { Peak action*: } 460 \times 10^{6} \mathrm{~A}^{2} \mathrm{~S} \\ & \text { Total volume: } 112 \times 10^{-3} \mathrm{~m}^{3} \\ & \text { Total mass: } 125 \mathrm{~kg} \\ & \text { Peak power: } 95 \mathrm{MW} \\ & \text { *Assumes an adiabatic system. }\end{aligned}$

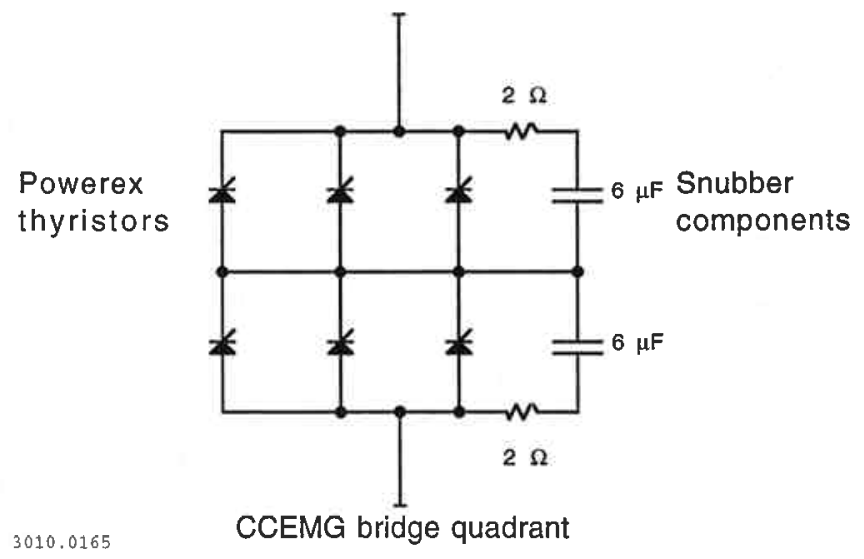

Fig. 3. Detailed schematic of R/I bridge 


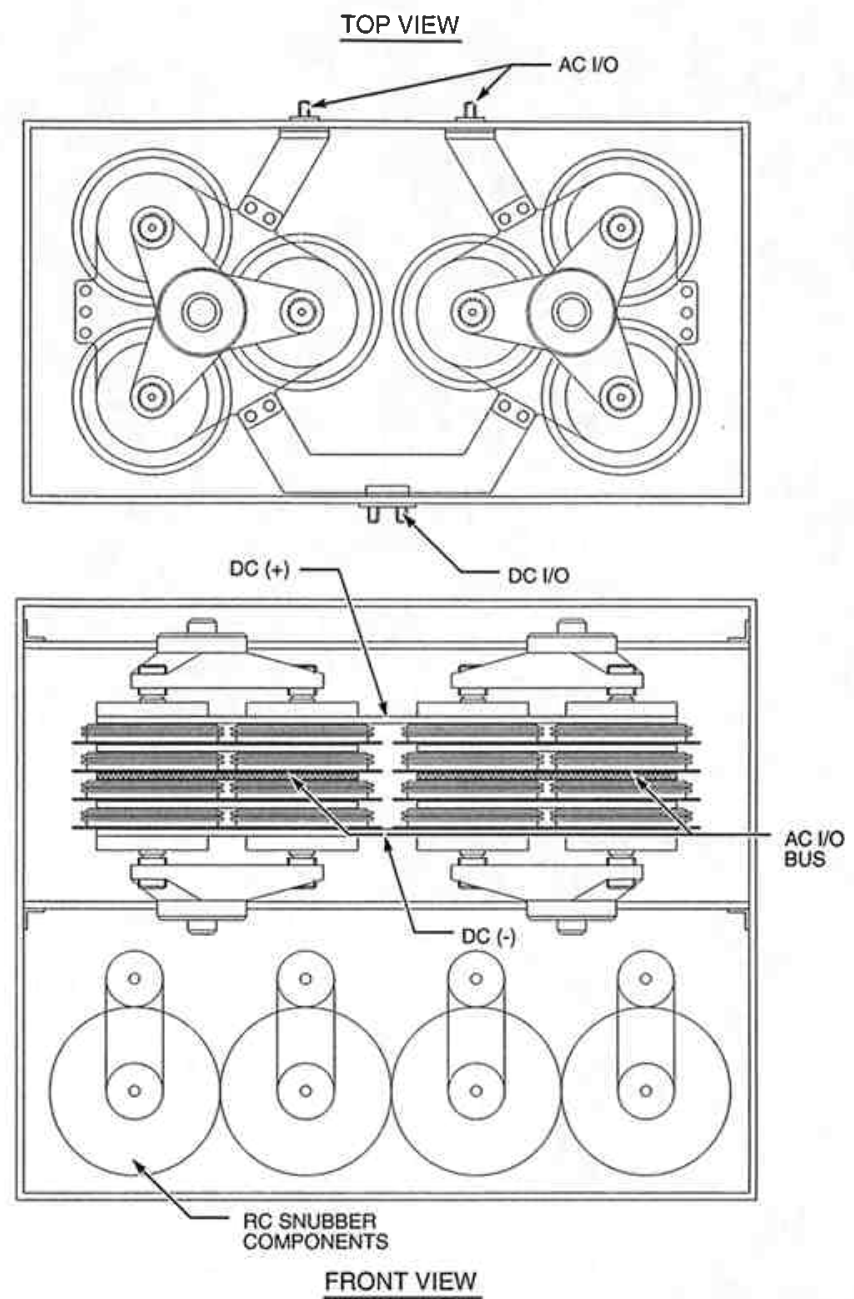

30100106

Fig. 4. Mechanical layout of R/I bridge, top and front views

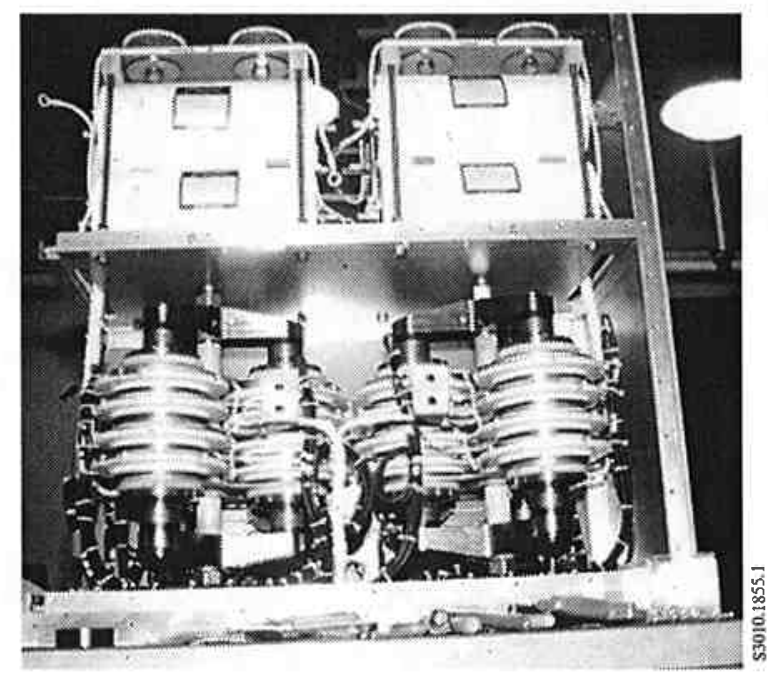

Fig. 5. Assembly of R/I bridge

\section{Mechanical Packaging}

The complete $R / I$ bridge is packaged as one unit. Volume of the complete bridge as well as matching the impedance of the current paths were the main reasons for a single unit design. Thermal issues were also a packaging concern. Copper plates were used as heat sinks in addition to electrical conductors. During multi-shot mode, heating in the thyristors will become an important concern, but should be managed with the packaging design. The complete $\mathrm{R} / \mathrm{I}$ bridge is made up of four identical quadrants of six thyristors each. The six thyristors of a quadrant are configured in a geometry consisting of two sets of three in parallel (Fig. 3). The bridge input power comes from the main coaxial bus. The ac is fed through flexible hexapolar cable into the center nodes of the thyristor stack. The rectified dc output leaves from the top of the bridge assembly and returns from the field coil on the bottom. Again, all conductors on the bridge output are flexible hexapolar cable up to the field coil terminals. The RC snubber components are arranged above the thyristors in another compartment [4]. The final bridge layout is shown in Fig. 4, and an assembly photo is shown in Fig. 5.

The bridge thyristor is a custom version of the Powerex TD20. The Powerex device was selected for performance and packaging reasons. The Powerex unit was available in a thin ceramic case, saving $30 \%$ in thickness compared to a standard press pak. These devices require a preload of $20,000 \mathrm{lb}(85$ $\mathrm{kN})$ per device. As shown in the layout, the bridge is assembled in two halves. Each half has a gang-clamping system. The gang-clamp uses a single alloy steel tie-rod with a titanium flange at each end. Each titanium flange has three selfaligning tilt pads that provide even pressure distribution across the thyristor stack. The preload is initially applied hydraulically, and maintained in operation by spring washers.

\section{Gate DRIVe}

One of the most critical areas of design for power electronic circuitry is proper device gating. Proper gating techniques are very important for reliably turning the thyristor on and off as well as for longevity of the device. Some of the earliest design work done on the CCEMG power electronics was to investigate what type of gate drive circuit would be optimal for this system. This early study found the best gate drive method for this system was a hard drive gate pulse with a 50 $\mu$ s back porch for the moderate to high $\mathrm{di} / \mathrm{dt}$ and $\mathrm{dv} / \mathrm{dt}$ requirements [4].

The gate drive circuit used for both the bridge and GSM is shown in Fig. 6. The circuit receives the command to gate from the cycle portion encoder (CPE) based on mission parameters. For the hard gate drive pulse, a $60 \mathrm{~V}, 3.5 \mathrm{~A}$ pulse is generated at the output of the pulse transformer. Since the pulse transformer used has a single primary turn and eight secondary turns, an insulated gate bipolor transistor (IGBT) was 

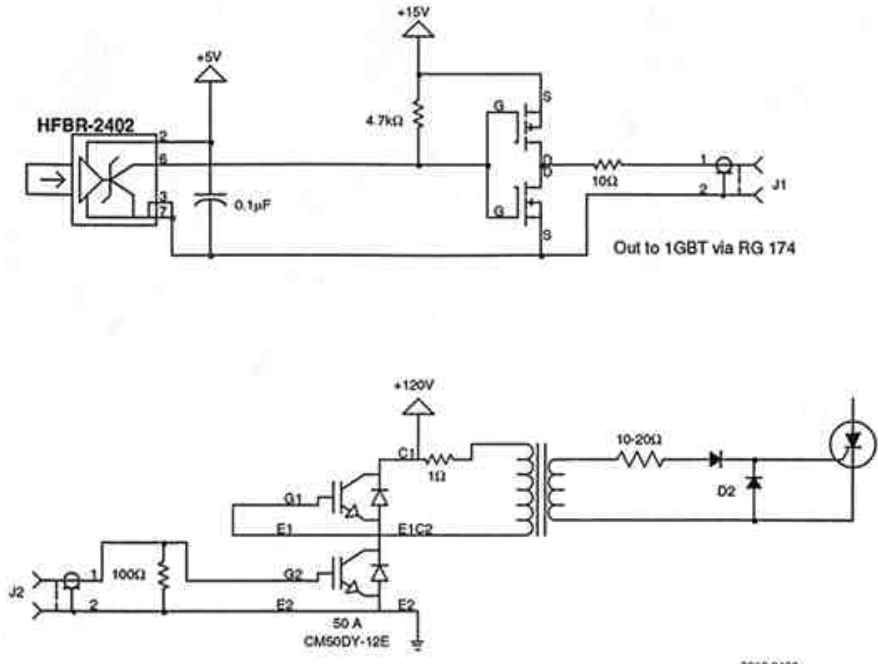

Fig. 6. Schematic of gate drive circuit

needed to drive the primary. The IGBT has strict gating requirements much like a thyristor. To satisfy these requirements, a complementary FET pair was used. The gate drive circuits have turned the thyristors on with $100 \%$ reliability as long as there was a sufficient forward voltage drop (at least $40 \mathrm{~V}$ ). The timing of the gate pulses with respect to actual compulsator voltage during a run is shown in Fig. 7. (Note that the gate pulses shown are the output of the pulse transformer and then are optically isolated, therefore, not the actual gate pulse used to drive the thyristor).

\section{Current Monitors}

To determine the actual current distribution during operation between thyristors, Rogowski coils are used to instrument each thyristor. The 24 Rogowski coil signals are conditioned and monitored by the bridge current sharing monitor (BCM). Since the bridge operates in quadrants, all thyristors in a quadrant are gated at the same time. Likewise, the BCM handles the 24 Rogowski signals as four groups of six signals each. After integration of the raw Rogowski signal, the average of each six-channel quadrant is formed. This establishes a quadrant average value for each of the four quadrants. The minimum acceptable sharing threshold is then added and subtracted from each average signal. This process yields a range to which each of the 24 individual integrated Rogowski signals are compared. Any signal from an individual Rogowski falling outside of the range will generate an error condition. The threshold levels are adjustable parameters, as are the gains for each raw Rogowski signal. With both of these items being adjustable, individual monitoring system differences can be calibrated out.

In addition to average current, positive and negative current flow is indicated for each channel using a similar ranging

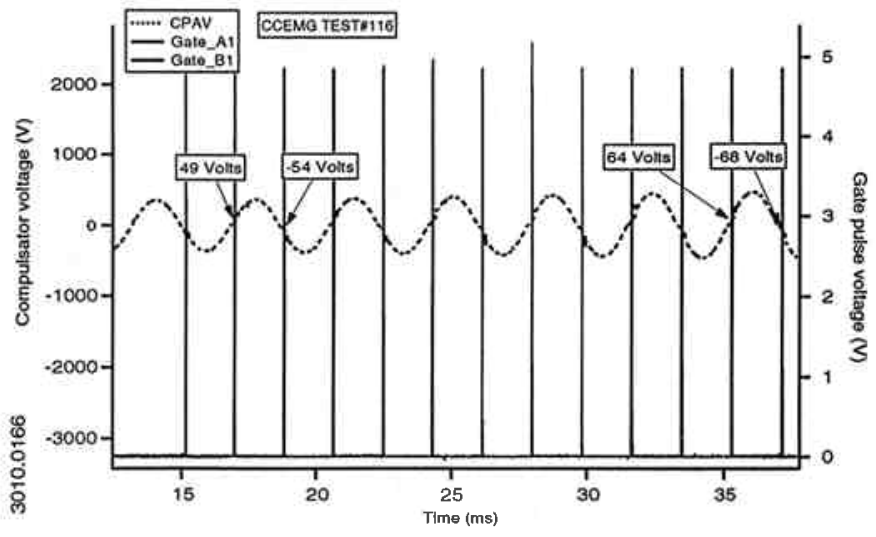

Fig. 7. Gate pulses and compulsator voltage

technique. The positive and negative levels are fixed conduction thresholds for each of the forward and reverse directions. Three resultant signals are possible: high, low, and negative. A fault condition is latched and displayed by quadrant on an array of LEDs. With the BCM system operating, evaluation of switch performance and troubleshooting a failed thyristor is possible.

The BCM also provides buffered individual integrated Rogowski signal outputs for data acquisition. As only six channels of data acquisition were available, bridge currents were sampled in quadrants. One quadrant was analyzed during test \#116. It was determined from the data that the six thyristors of the bridge shared current within the desired range of $10 \%$.

\section{FIM PERFormanCE}

The field initiation module (FIM) provides the initial seed current for the field coil. A simplified schematic of the FIM is visible on the overall system schematic (Fig. 1). The FIM consists of two Aerovox KM502EX350D21A capacitors connected in parallel for a total of $7,000 \mu \mathrm{F}$. The capacitors are initially charged from a high voltage dc supply, up to $4 \mathrm{kV}$ providing up to $50 \mathrm{~kJ}$ of energy. After the compulsator is motored to the desired discharge speed, the FIM is discharged into the field coil through dual Westcode N750CH45 thyristors. As the compulsator output terminal voltage increases, the FIM capacitors are passively recharged through dual high voltage diodes that are connected anti-parallel with the discharge thyristors. To insure long capacitor life, current limiting resistors are included in the charging circuit.

The FIM capacitor must be recharged from the compulsator terminals to meet CCEMG contract goals. To complete a CCEMG mission of 15 shots fired, the FIM must also discharge 15 times. During initial CCEMG system testing, passive FIM recharging has been demonstrated. Fig. 8 shows the 


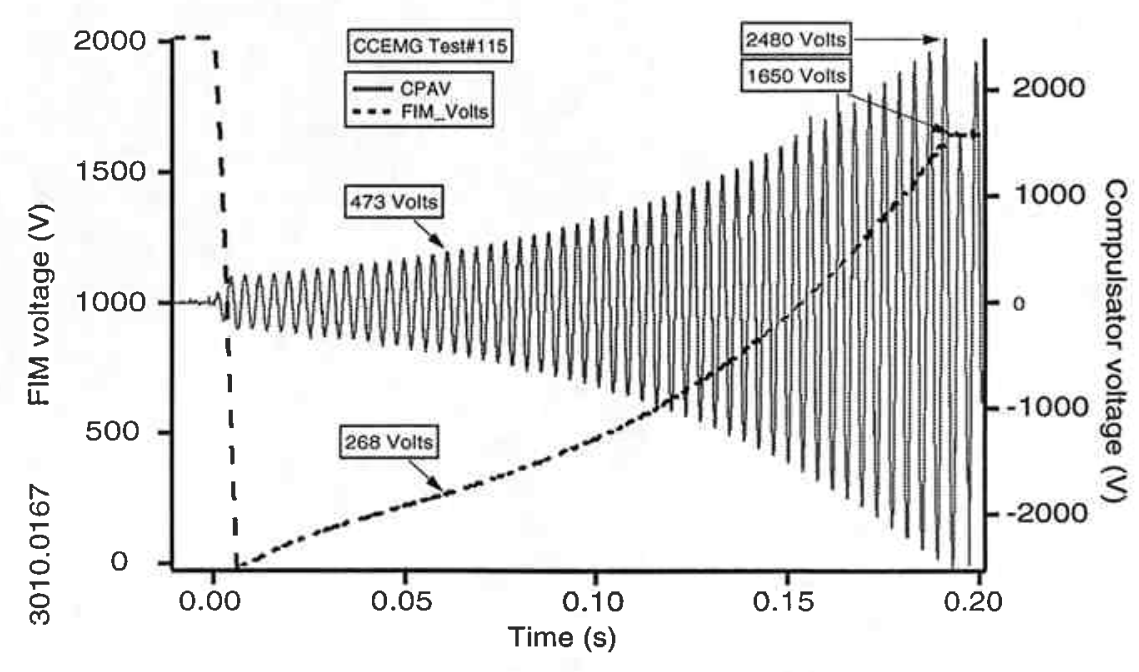

Fig. 8. Passive recharging of FIM with compulsator voltage

$2 \mathrm{kV}$ initial capacitor charge, capacitor discharge, and finally the FIM capacitor passively recharging. Final FIM capacitor charge voltage is $67 \%$ of compulsator terminal voltage. The FIM recharge energy was limited by a 15 degree bridge gating angle. This means that the energy between zero and 15 degrees was not utilized, therefore lowering the charging efficiency. For achieving CCEMG goals, $67 \%$ charge is an acceptable level.

\section{CONClusions}

Although the compulsator has not been tested to rated speed, several key components have been fully tested. As noted above, the bridge has charged the field coil current above its peak rating of $25 \mathrm{kA}$. During run \#116, the bridge rectified the field coil up to $30.5 \mathrm{kA}$, which should be the highest required current for testing. A summary of significant test data is shown in Table I. On the same test, each of the instrumented bridge thyristors of one quadrant indicated that current was shared between the devices within a $10 \%$ range. These results indicate the bridge has been tested to full design goals (with the exception of the total action rating) and verify that it will be able to handle the CCEMG system requirements for full testing. Fig. 9 shows the results of the bridge rectification from run \#84. The full-wave rectification of the bridge can be seen on the field coil current waveform along with resulting compulsator terminal voltage. Due to low compulsator speed, the rectification interval was much longer than at higher speeds. During initial CCEMG system testing, there have been no bridge related component failures.

The three other components of the power electronics skid, the FIM, GSM and EOS, were tested to full single-shot testing requirements and indicate they will meet the needs of full scale multi-shot testing. The FIM was charged to $3 \mathrm{kV}$ on

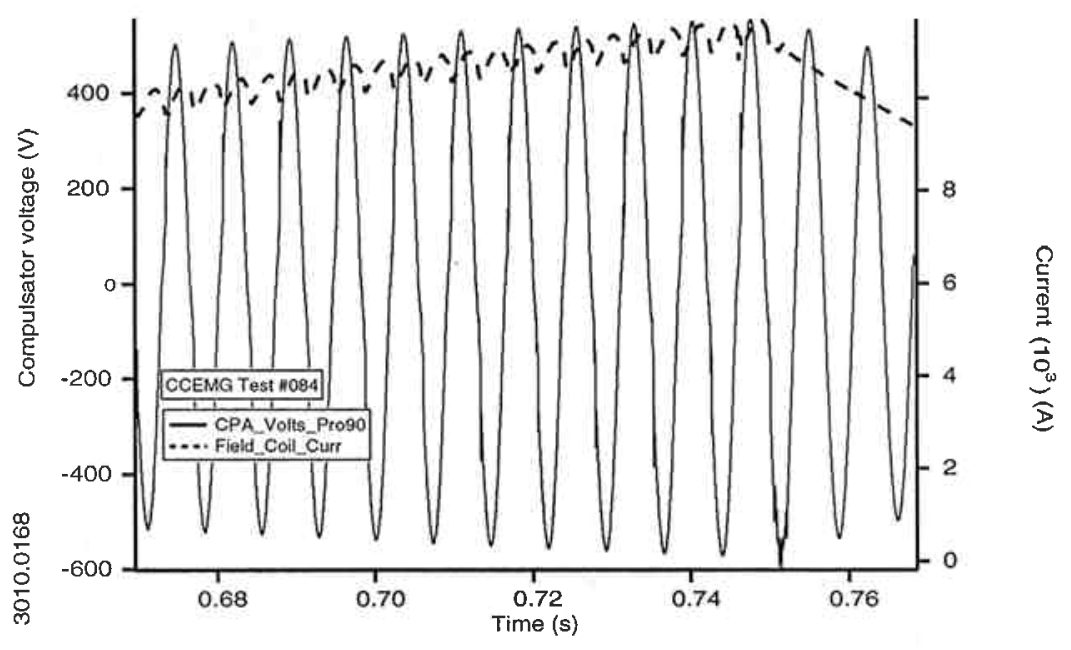

Fig. 9. Field coil current and compulsator 
run \#116 and successfully seeded current into the field coil for self-excitation. Passive recharging of the FIM was demonstrated on run \#115 and achieved a recharging level of $67 \%$ of peak compulsator voltage, a level adequate to achieve fullscale goals. In stand-alone testing, the FIM was charged to its peak rating of $4.5 \mathrm{kV}$ and discharged into an inductive load. On run \#116, the GSM switched $660 \mathrm{kA}$ into the gun during testing. On this test, the GSM saw a sinusoidal voltage of $2,835 \mathrm{~V}, 1 \mathrm{kV}$ below its rating. Although preliminary analysis indicates that a snubber may be required for higher peak current discharges, the GSM indicates that it can achieve system goals. The EOS has shown $100 \%$ reliability which is important for thermal protection of the compulsator during overcurrent or fault scenarios.

The power electronics skid components have been adequately tested during commissioning of the CCEMG system for full scale, single shot testing. In the initial single shot testing, no thermal problems have occurred. The thermal issues will be explored during the multi-shot testing sequence. Preliminary analysis of all of the components indicate that they should be able to achieve the system to full scale multishot testing goals for the CCEMG program.

\section{ACKNOWLEDGMENTS}

The authors would like to recognize the many UT-CEM and UDLP engineers, technicians and students that have worked long hours to make the CCEMG program a success. This effort is funded by the U.S. Army Armament Research Development and Engineering Center and the U.S. Marine Corps.

\section{REFERENCES}

[1] J.R. Kitzmiller, S.B. Pratap, M.D. Werst, C.E. Penney, T.J. Hotz, and B.T. Murphy, "Laboratory testing of the pulse power system for the cannon caliber electromagnetic gun systems (CCEMG)," submitted to the 8th EML Conference, April 1996.

[2] M.D. Werst, T.J. Hotz, J.R. Kitzmiller, C.E. Penney, and R.M. Telander, "Testing of the cannon caliber rapid fire railgun," submitted to the 8th EML Conference, April 1996.

[3] R.A. Lee, "Design and testing of a coaxial opening and solid state clos ing switch for the cannon caliber electromagnetic launcher system (CCEMG)," 10th IEEE Pulsed Power Conference, Albuquerque, NM, July 10-13, 1995.

[4] D.J. Wehrlen, R.A. Lee, R.F. Thelen, "Power electronics and controls for air core compulsator," IEEE Transactions on Magnetics, vol 31, no. 1, January 1995.

Table I. CCEMG selected single shot test summary

\begin{tabular}{|c|c|c|c|c|c|}
\hline $\begin{array}{c}\text { Parameter/Shot, Run \# } \\
\text { \& Date }\end{array}$ & Units & $\begin{array}{c}\text { Shot \#3 } \\
\text { Run \#107 } \\
1 / 24 / 96\end{array}$ & $\begin{array}{c}\text { Shot \#4 } \\
\text { Run \#114 } \\
2 / 5 / 96\end{array}$ & $\begin{array}{c}\text { Shot \#5 } \\
\text { Run \#115 } \\
2 / 7 / 96\end{array}$ & $\begin{array}{c}\text { Shot \#6 } \\
\text { Run \#116 } \\
2 / 9 / 96\end{array}$ \\
\hline $\begin{array}{l}\text { CPA Parameters } \\
\text { CPA Rotor Speed } \\
\text { FIM Charge } \\
\text { Field Amps } \\
\text { \% Design Field } \\
\text { Field Rise Time } \\
\text { CPA Peak AC Volts } \\
\text { Rotor Speed @ Discharge } \\
\text { Fire Angle (electrical) } \\
\text { Volts @ Trigger } \\
\text { Peak Gun Current } \\
\text { Pulse width } \\
\end{array}$ & $\begin{array}{c}\mathrm{rpm} \\
\mathrm{kV} \\
\mathrm{kA} \\
\% \\
\mathrm{~s} \\
\mathrm{~V} \\
\mathrm{rpm} \\
\circ \\
\mathrm{V} \\
\mathrm{kA} \\
\mathrm{ms} \\
\end{array}$ & $\begin{array}{c}7,580 \\
2 \\
22.0 \\
88 \\
0.192 \\
1,910 \\
7,251 \\
5 \\
166 \\
496 \\
3.30 \\
\end{array}$ & $\begin{array}{c}8,021 \\
2 \\
27.4 \\
110 \\
0.195 \\
2,510 \\
7,607 \\
5 \\
221 \\
599 \\
2.97 \\
\end{array}$ & $\begin{array}{c}8,000 \\
2 \\
27.4 \\
110 \\
0.195 \\
2,485 \\
7,653 \\
5 \\
221 \\
605 \\
2.97 \\
\end{array}$ & $\begin{array}{c}8,264 \\
3 \\
30.5 \\
122 \\
0.160 \\
2,835 \\
7,772 \\
5 \\
220 \\
660 \\
2.97 \\
\end{array}$ \\
\hline $\begin{array}{l}\text { Launcher/Armature Parameter } \\
\text { Primary Flatjack Pressure } \\
\text { ILP Mass } \\
\text { Load Force } \\
\text { ILP Muzzle Velocity } \\
\text { Muzzle Energy } \\
\text { Action } \\
\text { Breech Efficiency } \\
\text { Muzzle Current } \\
\text { Launcher L' }\end{array}$ & $\begin{array}{c}\mathrm{ksi} \\
\mathrm{g} \\
\mathrm{lbf} \\
\mathrm{m} / \mathrm{s} \\
\mathrm{kJ} \\
\mathrm{MA}^{2} \mathrm{~s} \\
\% \\
\mathrm{kA} \\
\mu \mathrm{H} / \mathrm{m} \\
\end{array}$ & $\begin{array}{l}10.0 \\
135.3 \\
3,100 \\
1,187 \\
95.3 \\
322 \\
44 \\
0.0 \\
1.00 \\
\end{array}$ & $\begin{array}{l}13.0 \\
148.4 \\
3,200 \\
1,729 \\
222 \\
495 \\
53 \\
125 \\
1.04\end{array}$ & $\begin{array}{l}13.0 \\
163.3 \\
3,360 \\
1,530 \\
191 \\
512 \\
49 \\
68 \\
0.98 \\
\end{array}$ & $\begin{array}{c}15.0 \\
154.5 \\
3,136 \\
1,900 \\
279 \\
589 \\
49 \\
212 \\
1.00\end{array}$ \\
\hline
\end{tabular}

